Article

\title{
Analysing the Role of Social Visits on Migrants' Social Capital: A Personal Network Approach
}

\author{
Gil Viry $^{1, *}$, Olga Ganjour ${ }^{2}$, Jacques-Antoine Gauthier ${ }^{3}$, Emmanuel Ravalet ${ }^{4}$ and Eric D. Widmer ${ }^{2}$ \\ ${ }^{1}$ School of Social and Political Science, University of Edinburgh, EH8 9LN, Edinburgh, UK; E-Mail: gil.viry@ed.ac.uk \\ 2 Department of Sociology, University of Geneva, 1205 Geneva, Switzerland; E-Mails: Olga.Ganjour@unige.ch (O.G.), \\ eric.widmer@unige.ch (E.W.) \\ ${ }^{3}$ Life Course and Inequality Research Centre, University of Lausanne, 1015 Lausanne, Switzerland; \\ E-Mail: Jacques-antoine.gauthier@unil.ch \\ ${ }^{4}$ Laboratory of Urban Sociology (LaSUR), École Polytechnique Fédérale de Lausanne, 1015 Lausanne, Switzerland; \\ E-Mail: emmanuel.ravalet@epfl.ch \\ * Corresponding author
}

Submitted: 17 September 2017 | Accepted: 22 November 2017 | Published: 28 December 2017

\begin{abstract}
There are concerns that migrants may be embedded in far-flung networks with support being less collective. The spatial dispersion of their relatives and friends would result in fragmented networks with lower solidarity and lower mutual trust than densely connected networks based on geographical proximity. This may be particularly true for migrants who rarely meet their relatives and friends face-to-face. Yet, it is unclear what role, if any, distant visits play in migrants' social capital. This article examines these issues using representative data from Switzerland and a combination of network and sequence analysis. Results show that migrants have more spatially dispersed networks, which, in turn, are associated with higher number of emotional support ties compared to respondents with spatially close networks, yet they are characterised by low cohesion and low trust. Distant visits only partly moderate the influence of spatial dispersion on social capital. People who frequently visit or host their far-flung relatives and friends have more transitive networks and fewer supportive ties than those who see them less often, but they do not have higher trust in them. Overall, distant visits have relatively little impact on social capital, suggesting a network effect that goes beyond dyadic relationships.
\end{abstract}

\section{Keywords}

distance; migration; network geography; personal networks; sequence analysis; social capital; social network analysis; social support; social visits; travel

\section{Issue}

This article is part of the issue "Regional and Urban Mobility: Contribution to Social Inclusion", edited by Janet Stanley (University of Melbourne, Australia) and John Stanley (University of Sydney, Australia).

(C) 2017 by the authors; licensee Cogitatio (Lisbon, Portugal). This article is licensed under a Creative Commons Attribution 4.0 International License (CC BY).

\section{Introduction}

Migration and diaspora research has long established that intimate networks of support and affection can exist across vast physical distances (e.g., Baldassar \& Merla, 2013; Cronin, 2015; Ryan, Sales, Tilki, \& Siara, 2009). With the increasing affordability of transport and telecommunications, individuals exchange love, affection and care with people who are living in different cities, regions and countries. There is also evidence that new internet-based technologies expand opportunities for individuals and families to sustain intimacy over long distances by facilitating a sense of being close and familiarity with each other's daily routines (Dekker \& Engbersen, 2014; Uy-Tioco, 2007; Valentine, 2006).

While emotional attachment with people living far apart can persist, migrants may develop personal networks, in which support is more individualised and less 
collective. Within such networks, migrants' 'significant others', i.e., the people they consider important, be they relatives, friends, colleagues, neighbours or members of various groups or associations, would be less likely to know and meet each other than within networks largely based on physical co-presence and geographical propinquity (Larsen, Axhausen, \& Urry, 2006; Wittel, 2001). Internet and mobile phones would be central for migrants in producing individualised networks, through what Wellman (2001) calls 'person-to-person' connectivity. Migrants, embedded in networks of weak or no ties between their significant others, or clusters of significant others, developed in different places, and often in different social contexts, would have bridging social capital as opposed to bonding social capital defined as networks characterised by cohesion, mutual trust and strong ties between its members (Coleman, 1988). Their spatially and socially fragmented personal networks would be less likely to enforce mutual obligations, norms and effective sanctions than densely connected personal networks characterised by greater homogeneity and higher normative control (Coleman, 1988; Putnam, 1993). On a positive side, these fragmented networks would provide diverse resources, novel information and autonomy to migrants (Burt, 2009; Granovetter, 1973).

The influence of migration and physical distance on social capital may, however, be moderated by social visits. Previous research has shown that occasional travel and face-to-face meetings are crucial for sustaining strong ties over distance (Elliott \& Urry, 2010; Larsen et al., 2006) and migrants who regularly visit and host their significant relatives and friends may put them in touch with one another. For instance, when migrants frequently host or visit their parents, intimacy may be established between them and migrants' partner and children. Migrants may also travel long distances to stay involved in densely connected groups of relatives or old friends in their place of origin. Ali and Holden (2006) have illustrated the central role played by post-migration tourism among Pakistanis living in the UK in maintaining strong ties and meeting social obligations with diasporas in the homeland.
Studies like Ali and Holden (2006) linking migration and more regular forms of mobility, such as social visits, are rare. To the authors' knowledge, no study has been proposed to analyse the joint effect of migration and distant visits on the size, structure and geography of personal networks. This article addresses this knowledge gap by examining personal networks in Switzerland using survey data from a representative sample of people living in Switzerland in 2011 and born in 1950-55 and 1970-75. Here, social capital is conceptualised as consisting of three dimensions: (1) the degree of trust in the members of one's personal network; (2) the size and (3) structure of one's emotional support network. People with high social capital refer to those who have many emotional support providers and high trust in their network members (see De Carlo \& Widmer, 2011, for a discussion about trust as social capital). Drawing on social capital literature (e.g., Coleman, 1988; Putnam, 1993), we distinguish two main types of social capital in terms of network structure. Bonding social capital refers to cohesive emotional support networks. In this kind of network, all members tend to support each other emotionally, which enforces bounded solidarity and mutual trust (see Figure 1 on the left). By contrast, bridging social capital refers to sparsely connected emotional support networks. In this kind of personal network, respondents tend to occupy a central position between their network members who hardly support each other emotionally (see Figure 1 on the right). In other words, bridging social capital is not identified here by the specific presence of weak ties, but by the absence of strong (i.e., emotionally supportive) ties.

In this study, migration is conceptualised holistically as individual histories. Migrants are defined as individuals who lived far from their birthplace most of their lives. Using the life history calendar method, retrospective data about moves were obtained. Sequence analysis techniques are used to identify typical patterns of residential mobility histories. This is a relevant measure, since it is well known from migration studies that social bonds are strengthened (and so more likely to be maintained) as length of residence increases (e.g., Lub-
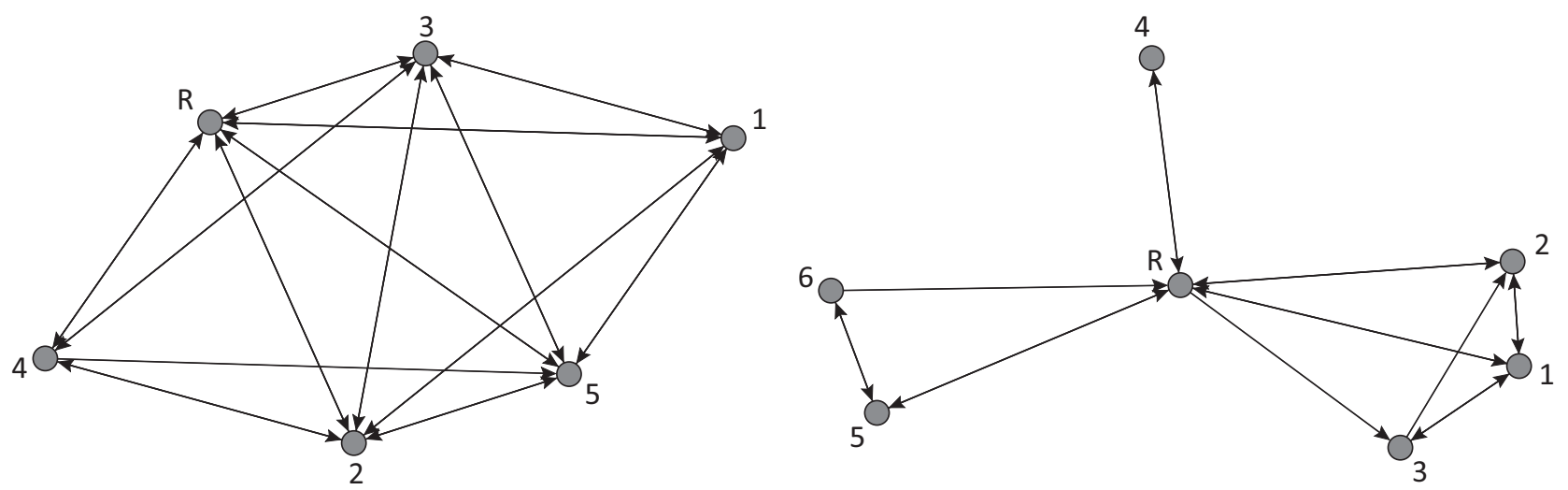

Figure 1. Bonding and bridging social capital. Reading: An arrow from A to B indicates that A provides emotional support to $B$ (from the respondent R's point of view). 
bers et al., 2010; Magdol \& Bessel, 2003). This study investigates how respondents' social capital is influenced by residential mobility histories, the spatial dispersion of their personal networks and social visits from or to their network members. We first examine whether migrants have higher bridging social capital than respondents who remained close to their birthplace. We then evaluate whether frequent visits between respondents and their far-flung network members moderate the influence of spatial dispersion on social capital.

\section{Theoretical Background and Previous Research}

Many scholars in the field of mobility and social network research argue that today's social life is less based on propinquity within the immediate neighbourhood and more on connectivity, due to profound transformations in technology, work and lifestyle (Larsen et al., 2006; Rainie \& Wellman, 2012; Urry, 2007; Wittel, 2001). In this 'network sociality', personal relationships are fluid and changing as people move to different milieus and life projects. Social obligations to friends and family are more a matter of negotiation and choice than strict determination by the social structures and norms. This networked pattern would be even more marked for migrants who would build new relationships and negotiate social obligations to existing ones across multiple places. Empirical studies show complex changes in migrants' personal networks, which reflect their selection and adaptation processes in the new environment. Using longitudinal network data on 25 Argentinian immigrants in Spain, Lubbers et al. (2010), for example, showed a high turnover in migrants' relationships, with a strong tendency toward transitivity (tendency that one's friends' friends are likely to become one's own friends). However, the overall composition, size and structure of networks appeared to be relatively stable over time. Using a nationally representative sample of core personal networks from Switzerland, Viry (2012) showed that spatially dispersed networks had a bridging structure. But he also found that long-distance ties were more transitive than local ones. The two effects of distance acted in the opposite direction and tended to cancel each other out.

In a networked social life, virtual and physical mobility is central (Urry, 2007). Information communication technologies facilitate a sense of involvement in the daily lives of loved ones and offer ways to exchange thoughts, emotions and feelings, intimacy and sometimes care (telecare) over large geographical distances (Uy-Tioco, 2007; Valentine, 2006). However, mediated interaction cannot fully substitute for face-to-face moments and physical intimacy because of its disembodied nature (Boden \& Molotch, 1994; Valentine, 2006). Occasional visits are necessary, as being physically together involves touch, body language and rich conversation that help maintain intimacy and trust. Social visits also signal commitment. Visiting or hosting friends and relatives requires people to set aside not only a specific time but also a shared physical place. Finally, social obligations also require intermittent co-presence, for example for attending important social events, such as birthdays and celebrations.

Yet, regular travel requires important resources of money, time, good health, access and skills (e.g., Axhausen \& Kowald, 2015; Kaufmann, Bergman, \& Joye, 2004; Urry, 2012). Individuals who lack these resources may have difficulties in maintaining strong relationships over large distances. Several surveys have stressed the decay of support and care with the increase of spatial distance (e.g., Mok, Wellman, \& Carrasco, 2010; Mulder \& van der Meer, 2009). Some significant relationships are therefore likely to turn non-significant after migration. Conversely, because migrants need close-by strong relationships to regularly share pleasurable moments and create a sense of home, they are likely to develop new significant relationships in the place of destination. Empirical evidence suggests that peripheral relationships (extended kin, neighbours, co-workers, distant friends) are more vulnerable to physical distance than relationships with parents, children and siblings, with strong friends lying in between (Lubbers et al., 2010; Pollet, Roberts, \& Dunbar, 2013; Widmer \& Viry, 2017; Wrzus, Hänel, Wagner, \& Neyer, 2013). These differences are explained by the normative power and density of connections that enforce mutual obligations within families, and, to some extent, strong friendship groups.

\section{Hypothesis}

Three hypotheses are explored in this study:

(i) Because migrants are likely to maintain significant ties with family and friends in their places of origin, we expect that respondents who have moved longer distances from their birthplace have more geographically dispersed networks, which in turn are associated with bridging social capital. These migrants would occupy a central network position in which they would bridge geographically distant network members or clusters of network members.

(ii) We expect that distant visits to or from far-flung network members mitigate the effect of spatial dispersion on bridging social capital. Individuals who regularly visit and host their significant relatives and friends are more likely to put them in touch with one another than those who meet them less often. In the other direction of causality, migrants are likely to travel long distances to stay involved with cohesive groups in their place of origin, such as parents and siblings or groups of old friends. Respondents who frequently visit or host their farflung network members are thus expected to have more bonding social capital (and therefore less bridging social capital) than those who meet them less often. 
(iii) Finally, we expect that frequent distant visits are associated with high social capital. Because maintaining strong relationships over distances requires travel and face-to-face contacts, we hypothesise that individuals who regularly visit and host their significant relatives and friends are expected to report higher trust in them and have more emotional support providers than those who meet them less often.

A conceptual model summarising the relationships between the key variables is presented in Figure 2.

\section{Data and Measures}

The data come from the Family tiMes survey conducted in Switzerland in 2011. A representative sample of 803 men and women living in Switzerland and from two birth cohorts (1950-55 and 1970-75) were selected from the population register of the Swiss Federal Statistical Office (response rate: 55\%). Face-to-face (CAPI) interviews were conducted at respondents' homes by trained interviewers of a survey institute. The questionnaire included two main instruments: (1) a Life History Calendar (Morselli et al., 2016) to collect retrospective life course data in various life domains, such as family, work and residential location; and (2) the Family Network Method (Widmer, Aeby, \& Sapin, 2013) for collecting information on the composition and structure of the respondents' personal networks.

The Family Network Method belongs to instruments measuring cognitive networks. In such instruments, a given individual, usually referred to as ego or the focal person, is asked to report the relationships existing between all individuals in a group (Krackhardt, 1987). Various studies have successfully used a cognitive network approach for studying not only face-to-face interactions but also discussion networks (Marsden, 1987), friendship ties (Pittinsky \& Carolan, 2008), advice and instrumental support provision (Krackhardt \& Kilduff, 2002), emotional closeness, support and liking (Freeman \& Webster, 1994; Kenny, Bond Jr, Mohr, \& Horn, 1996; Widmer, 2016) or leadership and hierarchy (Brands, Menges, \& Kilduff, 2015). Overall, the aim of such studies is not so much about testing the accuracy of non-behavioural measures of interactions (Coenders, Kogovšek, Hlebec, \& Coromina, 2014), but rather to see how cognitive patterns about interactions relate to critical dimensions of social embeddedness such as social class, gender, statuses and roles in various organisations or groups (Brands, 2013).
In this study, personal networks refer to the set of individuals, the so called significant others or alters, who are considered meaningful or important in some regard by the respondent, and the emotional support ties existing between them from the respondent's point of view (Widmer, 2016; Widmer et al., 2013). Personal networks are related to the social, emotional and symbolic significance of network members for the respondent. Such significance may or may not be associated with regular interactions, either face-to-face or by telecommunication. Personal networks are therefore not necessarily interactive networks. Respondents were asked to nominate their significant others, be they relatives, friends, colleagues, neighbours or members of various groups or associations, using the following name-generator question: 'Over the past year, who are the individuals who have been very important to you, even if you have not get on well with them?' [authors' translation]. Respondents could mention up to twenty people. They were also asked to report the frequency of contact (both faceto-face and mediated) with each of them in six categories (1. Daily or almost daily, 2. Several times a week, 3. Once a week, 4. Several times a month, 5. Several times a year, 6 . Never or almost never) and the degree of trust respondents had in these people in five categories (1. Absolute trust, 2. Great trust, 3. Some trust, 4. Little trust, 5. No trust at all). Additionally, respondents were asked to report who provides emotional support to whom within the network ( $0=$ No, $1=$ Yes), both between respondents and network members and among network members. The question was: 'Among the persons you cited, who provides emotional support to you if needed?'. The same question was then asked in turn for each cited person, for instance 'who provides emotional support to person $B$ if needed?'.

\subsection{Migration}

Sequence analysis was used to capture residential mobility behaviours holistically. Based on the Life History Calendar, the residential postcodes from birth until the time of interview were collected for each semester of age for all respondents. The road distance (in $\mathrm{km}$ ) between the residence and the birthplace was inferred using routing software modelling the Swiss road network and grouped into five categories $(1.0-10 \mathrm{~km}, 2.11-40 \mathrm{~km}$, 3. 41-100 km, 4. 101-500 km and 5. abroad). We constructed individual sequences and computed the degree of dissimilarity between pairs of individual sequences (Gauthier, Bühlmann, \& Blanchard, 2014). We then ap-

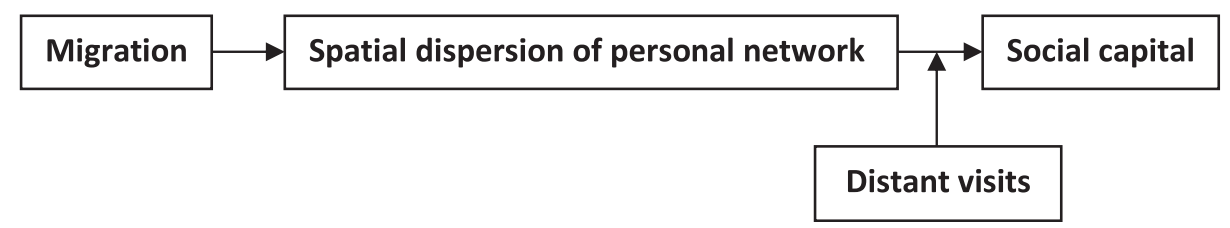

Figure 2. Conceptual model of the relationship between migration and social capital. 
plied a clustering procedure to these dissimilarity scores to group together similar sequences and produce a typology of migration histories. Standard quality indices identified an optimal five-type solution (Rousseeuw, 1987), which is presented as chronograms in Figure 3. The $x$-axis indicates respondents' age (in semesters) and the $y$-axis indicates the relative distribution of the five distance categories at a given age. The first type (' $0-10 \mathrm{~km}$ ', 38\%) is composed of individuals who spent most of their life in their birthplace or at a distance of a few $\mathrm{km}$ from it. The individuals grouped in the second type (' $11-40 \mathrm{~km}$ ', 19\%) moved mainly between ages of 16 and 30 to locations that are up to several tens of $\mathrm{km}$ away from their birthplace. In the third type (' $41-100 \mathrm{~km}$ ', 13\%), relocation occurs slightly earlier (between ages 15 and 25) and at a greater distance than the previous type. The fourth type ('101-500 km', 12\%) reveals a similar pattern regarding the timing of move, but is characterized by a relocation within Switzerland of at least $100 \mathrm{~km}$ from the birthplace. Finally, the fifth type ('Abroad', 18\%) is composed of individuals who migrated to Switzerland, mainly between the ages of 15 to 35 . Most of these individuals did not subsequently move far from their first location in Switzerland. In this study, we define migrants as individuals who moved and lived far from their birthplace for a significant period of their lives. We can therefore consider individuals of types 5, 4 and, to some extent, 3 as migrants.

\subsection{Social Capital}

The degree and type of social capital was measured by six network indices. (1) The personal network size is the number of 'very important' persons cited by the respondents. (2) The number of emotionally supportive ties is the number of significant others who were perceived by the respondents as giving them emotional support. (3) Respondents' trust in their significant others was measured by averaging the degree of trust in each network member on a scale ranging from 1 (no trust at all) to 5 (absolute trust). (4) Network density is the ratio of existing emotional support ties to the total possible. This index captures the overall network cohesion. (5) Network transitivity indicates the proportion of transitive triads in the network. A transitive triad is a group of three network members (including or not the respondent), where if $X$ gives emotional support to $Y$ and $Y$ gives emotional support to $Z$, then $X$ also gives emotional support to $Z$. Triads with no or only one tie were not included in the calculation. Transitivity is another index of network cohesion, which reflects the tendency of network actors to form cliques. Transitivity has been proved to play an important role in the process of tie formation over time (e.g., Lubbers et al., 2010). (6) Respondents' betweenness centrality indicates the extent to which respondents occupy a central position, where they bridge their otherwise disconnected significant others in the emotional support network. Respondents with high social capital refer to those who have high trust in and many emotion- ally supportive ties with their network members. Respondents with high bonding social capital refer to those who have high scores of density and transitivity and low score of betweenness centrality. Conversely, respondents with high bridging social capital display low scores of density and transitivity and high score of betweenness centrality. Because these six measures were not normally distributed (see Appendix A), they were dichotomized at the median into high versus low scores to be used as dependent variables in regression models. Appendix B displays measures of the strength of association between the dichotomized variables.

\subsection{Network Spatial Dispersion}

Based on the residential postcodes of network members (as reported by respondents), the road distance (in $\mathrm{km}$ ) between the respondents and their significant others was inferred using the routing software. The spatial dispersion of personal networks was measured as the natural logarithm of the average road distance between the respondents and their significant others. A threshold distance of $500 \mathrm{~km}$ was used between respondents and their significant others living abroad, which is about the greatest road distance between any two locations in Switzerland. We used the natural logarithm to reduce the effect of transnational networks, as we expect that absolute changes in distance are more important for short distances than long distances. The logarithm was also used to counter deviations from normality and reduce the bias because we do not know the exact distance to network members living abroad. The average network spatial dispersion was $2.5 \mathrm{In} \mathrm{km}$ (median $=2.6 \mathrm{ln} \mathrm{km}, \mathrm{sd}=1.9 \mathrm{In} \mathrm{km}$ range: $0-6.2 \ln \mathrm{km}$ ).

\subsection{Distant Visits}

Distant visits were measured as the average number of In km travelled per year by ego and their significant others to meet each other. This index captures the extent to which network members activate their travel resources (especially in time and money) and make the effort to physically meet despite geographical separation. It was derived from the road distance and frequency of face-toface contact between respondents and their significant others. We first recoded the frequency of face-to-face contact as the number of visits per year (e.g., weekly $=52$ visits per year) and multiplied this number by the natural logarithm of the road distance between the respondent and the significant other (abroad $=500 \mathrm{~km}$; same postcode $=0$ ). Scores were then summed across the significant others and normalised by dividing by the number of significant others who do not have the same postcode as the respondent (non-null distance). The average index score was $126.6 \mathrm{ln} \mathrm{km}$ (median $=59.7 \mathrm{ln} \mathrm{km}, \mathrm{sd}=210.8$ In km, range: 0-1864 In km). Because of the way the index is constructed, its correlation with networks spatial dispersion is relatively high (Kendall correlation coef- 


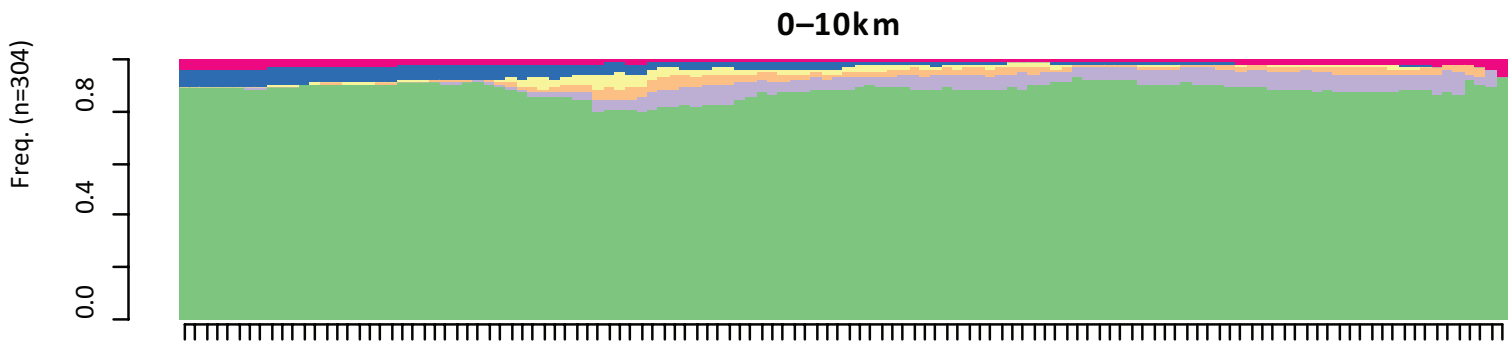
$\begin{array}{llllllllllllllllllll}s 2 & s 7 & s 13 & s 19 & s 25 & s 31 & s 37 & s 43 & s 49 & s 55 & s 61 & s 67 & s 73 & s 79 & s 85 & s 91 & s 97 & s 104 & s 112 & s 120\end{array}$

\section{$11-40 \mathrm{~km}$}

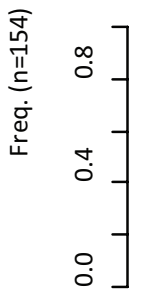

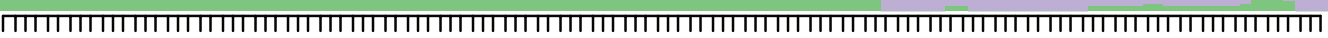
$\begin{array}{llllllllllllllllllll}\text { s2 } & s 7 & s 13 & s 19 & s 25 & s 31 & s 37 & s 43 & s 49 & s 55 & s 61 & s 67 & s 73 & s 79 & s 85 & s 91 & s 97 & s 104 & s 112 & s 120\end{array}$

41-100km

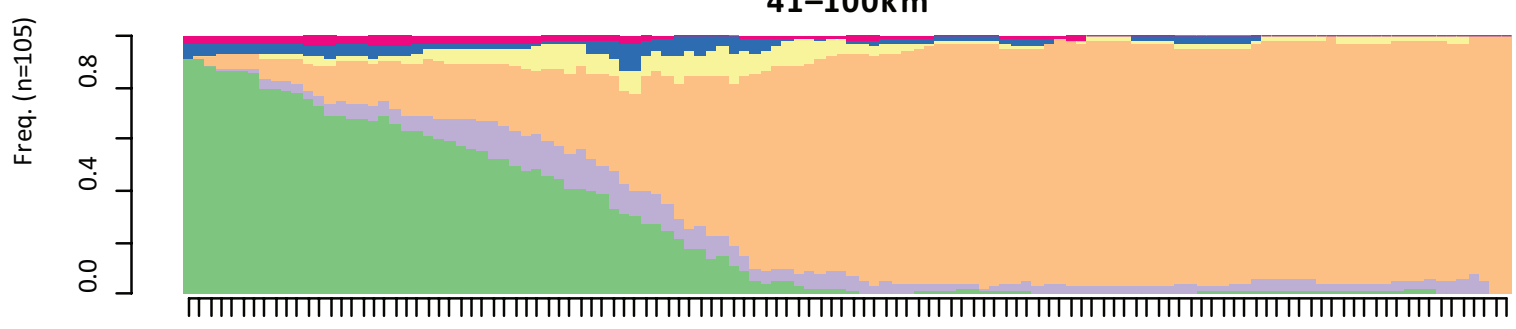
$\begin{array}{llllllllllllllllllll}\text { s2 } & \text { s7 } & \text { s13 } & \text { s19 } & \text { s25 } & s 31 & s 37 & s 43 & s 49 & s 55 & s 61 & s 67 & s 73 & s 79 & s 85 & s 91 & s 97 & s 104 & s 112 & s 120\end{array}$
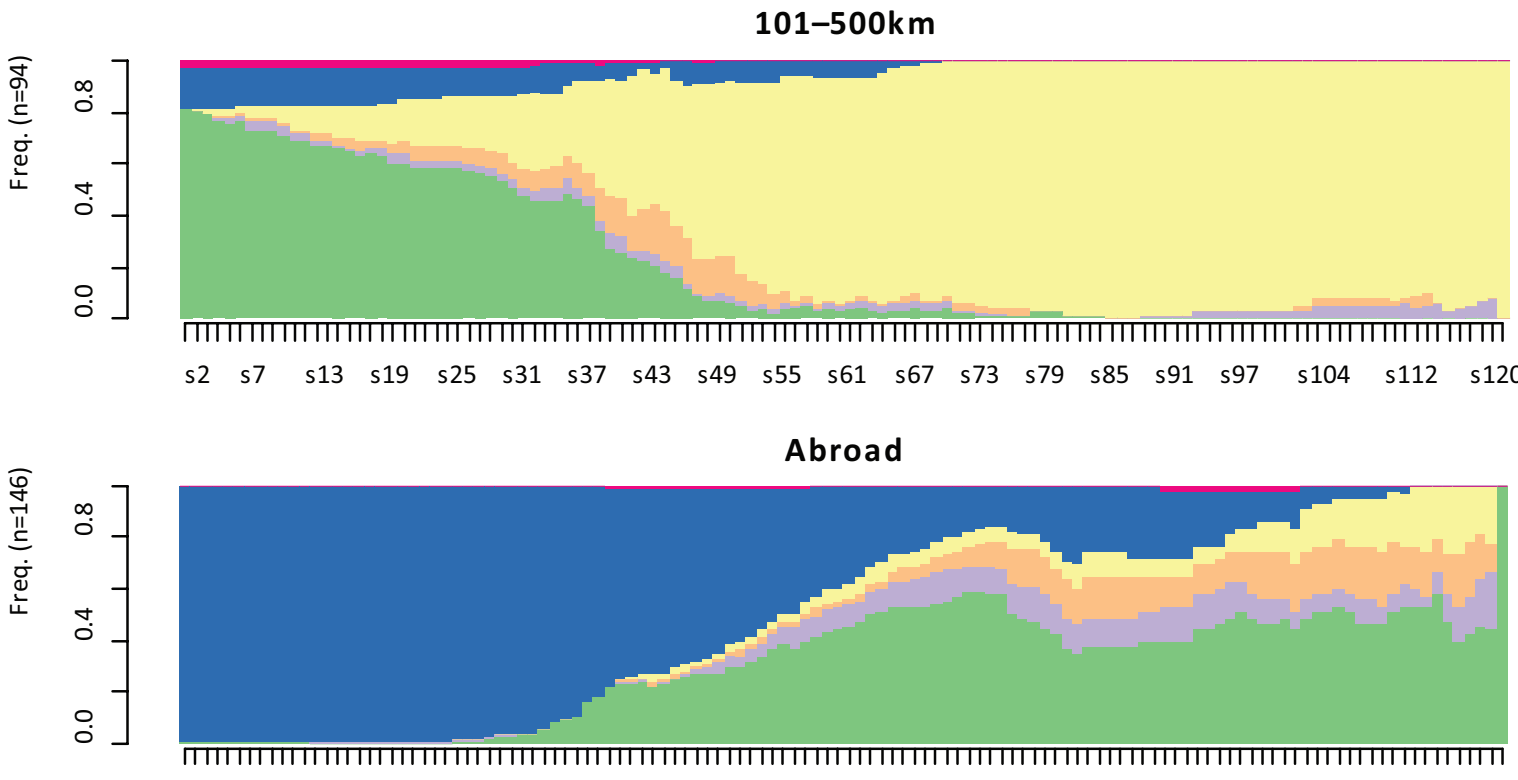
$\begin{array}{llllllllllllllllllll}\text { s2 } & \text { s7 } & s 13 & s 19 & s 25 & s 31 & s 37 & s 43 & s 49 & s 55 & s 61 & s 67 & s 73 & s 79 & s 85 & s 91 & s 97 & s 104 & s 112 & s 120\end{array}$

$$
\text { 0-10km } \square \text { 11-40km } \square \text { 41-100km } \square \text { 101-500km } \square \text { abroad } \square \text { missing }
$$

Figure 3. Typology of migration histories. 
ficient $=0.36, p=2.2 \mathrm{e}-16$ ). In particular, respondents who live very close to relatives and friends have a low score by definition, because they do not need to activate their travel resources and make much effort to meet them physically. By contrast, the index varies significantly among respondents with more spatially dispersed networks, depending on the number of long-distance visits. Taking the logarithm of distances has the same advantages as for the network spatial dispersion (see above).

This index has three drawbacks. First, it only includes information on social visits between respondents and their significant others. Data on social visits between all network members were not available. Second, it is impossible to know whether it was the respondents or their significant others who physically travelled. Third, strictly speaking, the index is not the average number of $\mathrm{In} \mathrm{km}$ travelled per year, since respondents may only need one visit to meet several significant others who live together (or close by). This may be especially true for visits to very distant significant others. Since the data do not include information about whether significant others lived together or not, we cannot exclude multiple-counting errors. At the same time, the solution of counting only once the visits to different people living in the same place (same postcode) is problematic, because individuals who travel to a specific place do not necessarily visit all their significant others living there and because it is not necessarily the respondents who travelled but their significant others. We also tested some cruder measures of distant visits (average number of visits at a distance greater than a certain threshold, e.g., $40 \mathrm{~km}$ ) and finally rejected them, because they did not yield more meaningful results.

\subsection{Control Variables}

Respondents' socio-demographics, the duration of relationships and network composition were included as control variables in the analysis, since the literature shows that these factors are significantly related to both migration and social capital. Respondents' sociodemographics include sex, birth cohort, level of education, activity rate, civil status and citizenship (see Appendix $C$ for the sample description). The duration of relationships was measured by the average number of years respondents had known their significant others. The composition of personal networks was measured using a clustering procedure based on the types of relationships between respondents and their significant others (e.g., brother). 48 respondents (6\%) were excluded from the analysis, because they mentioned no or only one important person. Seven types of network composition were identified (see Appendix D): (1) female friends (25\%); (2) nuclear family (partner and children) (23\%); (3) family of origin (parents, siblings and partner) (13\%); (4) siblings (12\%); (5) male friends and partner (11\%); (6) extended kin (8\%); and (9) colleagues (7\%).

\section{Results}

Table 1 shows the results from a linear regression model to test the effect of migration history on the spatial dispersion of personal networks. Network composition and socio-demographic variables are included as other predictors of network spatial dispersion. Results indicate that migrants have more spatially dispersed networks than those who lived in, or close to, their birthplace most of their lives. Compared with respondents who lived in the immediate vicinity (within $10 \mathrm{~km}$ ) of their birthplace, those who lived $40 \mathrm{~km}$ or more from where they were born and international migrants had more geographically spread out networks, regardless of the composition of their personal networks. Respondents who cited a relatively high proportion of extended kin, siblings, parents, and to a lower extent colleagues and female friends, had more spatially dispersed networks than those who mainly cited their partner and children. In contrast, respondents with more male friends had on average relationships closer in space. A high level of education is also positively associated with spatially dispersed networks. Finally, divorced or widowed people and foreigners had on average more distant significant others than married and Swiss people, respectively.

Tables 2 and 3 show the results from logistic regressions using social capital indices as dependent variables. In Models 1, the network spatial dispersion, migration history, network composition and socio-demographic variables are included as predictors. Models 2 and Models 3 add distant visits and the interaction effect between distant visits and network spatial dispersion, respectively. The interaction effect aims to test whether distant visits have different effects on social capital depending whether respondents have spatially dispersed or spatially close networks. Because the number, strength and structure of social relationships may directly influence spatial dispersion and social visits, these regression models cannot be regarded as strictly causal, but as a way to study associations, with both causal directions possible. For example, transitive networks may encourage social visits but social visits can also contribute to network transitivity. Likewise, densely connected personal networks may discourage individuals to move away, but, conversely, physical distance can cause lower network density.

Results from Models 1 indicate that network spatial dispersion is strongly associated with social capital, when controlling for network composition and duration of the relationships. Respondents who live on average far from their significant others tend to have larger networks and more support providers than respondents who live closer to them. Yet, they have a lower degree of trust in their significant others and more sparsely connected networks (low density and low transitivity). They hold a central position between their geographically distant network members who are less likely to support each other than in local networks. Results also show that mi- 
gration history has little effect on social capital. This is also true when the network spatial dispersion is removed from regression models (not shown). However, we observe a tendency towards increased transitivity among respondents who have moved long distances from their birthplace. In particular, international migrants have significantly more transitive networks than individuals who remained close to their birthplace, when controlling for the network spatial dispersion. This confirms earlier findings that migrants tend to develop transitive ties in the new location and are more likely to maintain transitive ties than non-transitive ones at the place of origin (Lubbers et al., 2010; Viry, 2012).

Models 2 and 3 indicate that, overall, distant visits have relatively little impact on social capital. Contrary to our expectation, distant visits do not mitigate the influence of spatial dispersion on network density and social trust. In particular, people who are frequently visit- ing or hosting their far-flung network members do not trust them more than those who see them face-to-face less often. In line with our expectations, however, results from Models 3 show that distant visits mitigate the influence of spatial dispersion on network transitivity. Distant visits to or from network members living on average far away are related to high transitivity. Frequent visits to people living on average close by are conversely associated with low transitivity. Models 3 also show that frequent visits impact differently the number of emotional support ties received by respondents, depending on the network spatial dispersion. Those who frequently visit or host their geographically distant network members have significantly fewer support providers. Because of resource constraints, individuals may be unable to frequently travel to more than a few significant people living far away. Conversely, frequent visits tend to impact positively the support received when network members

Table 1. Linear regression of the network spatial dispersion (In km) (beta coefficients).

\begin{tabular}{|c|c|}
\hline \multicolumn{2}{|c|}{ Migration histories (Ref. 0-10 km) } \\
\hline $11-40 \mathrm{~km}$ & .22 \\
\hline $41-100$ km & $.67^{* *}$ \\
\hline $101-500 \mathrm{~km}$ & $1.01 * * *$ \\
\hline Abroad & $1.15^{* * *}$ \\
\hline \multicolumn{2}{|c|}{ Network composition (Ref. Nuclear family) } \\
\hline Female friends & $1.01 * * *$ \\
\hline Family of origin & $1.23 * * *$ \\
\hline Sibling & $1.38 * * *$ \\
\hline Partner and male friends & .13 \\
\hline Extended kin & $1.39 * * *$ \\
\hline Colleagues & $1.12^{* * *}$ \\
\hline \multicolumn{2}{|l|}{ Duration of relationships } \\
\hline \multicolumn{2}{|l|}{ Sex (Ref. Male) } \\
\hline Female & .13 \\
\hline \multicolumn{2}{|l|}{ Birth cohort (Ref. 1950-55) } \\
\hline 1970-75 & -.09 \\
\hline \multicolumn{2}{|c|}{ Level of education (Ref. Low secondary) } \\
\hline Upper secondary & .68 \\
\hline Vocational & $.51 *$ \\
\hline University & $.94 * * *$ \\
\hline \multicolumn{2}{|l|}{ Activity rate (Ref. Full-time) } \\
\hline Part-time (51-80\%) & -.03 \\
\hline Part-time ( $50 \%$ or less) & .04 \\
\hline Self-employed & .16 \\
\hline Non-active & -.19 \\
\hline \multicolumn{2}{|l|}{ Civil status (Ref. Married) } \\
\hline Divorced or widowed & $.42 *$ \\
\hline Single & .13 \\
\hline \multicolumn{2}{|l|}{ Citizenship (Ref. Foreigner) } \\
\hline Swiss & $-.54 *$ \\
\hline$\overline{R^{2}}$ & $.1985^{* * *}$ \\
\hline
\end{tabular}


Table 2. Logistic regressions of social capital (beta coefficients).

\begin{tabular}{|c|c|c|c|c|c|c|c|c|c|}
\hline & \multicolumn{3}{|c|}{ Network size } & \multicolumn{3}{|c|}{ Number of supportive ties received } & \multicolumn{3}{|c|}{ Trust in network members } \\
\hline & 1 & 2 & 3 & 1 & 2 & 3 & 1 & 2 & 3 \\
\hline Network spatial dispersion & $.24 * * *$ & $.25 * * *$ & $.26 * * *$ & $.25 * * *$ & $.25 * * *$ & $.28 * * *$ & $-.11 *$ & $-.11 *$ & $-.12 *$ \\
\hline Distant visits & & -.0004 & .0000 & & -.0002 & .0021 & & .00 & -.0013 \\
\hline Network spatial dispersion $\mathrm{x}$ distant visits & & & -.0001 & & & $-.0006 *$ & & & .0003 \\
\hline \multicolumn{10}{|l|}{ Migration histories (Ref. 0-10 km) } \\
\hline $11-40 \mathrm{~km}$ & .24 & .24 & .24 & .13 & .13 & .12 & .04 & .04 & .05 \\
\hline $41-100$ km & .17 & -.18 & -.18 & -.39 & -.40 & -.39 & -.34 & -.34 & -.34 \\
\hline $101-500 \mathrm{~km}$ & -.37 & -.38 & -.38 & -.14 & -.15 & -.11 & .04 & .04 & .02 \\
\hline Abroad & -.15 & -.17 & -.17 & -.55 & -.56 & -.53 & .46 & .46 & .46 \\
\hline \multicolumn{10}{|l|}{ Network composition (Ref. Nuclear family) } \\
\hline Female friends & -.49 & -.47 & -.47 & $-1.28 * * *$ & $-1.27 * * *$ & $-1.29 * * *$ & -.31 & -.31 & -.30 \\
\hline Family of origin & .04 & .04 & .02 & -.70 & -.70 & $-.76^{*}$ & .23 & .23 & .26 \\
\hline Sibling & $-.73^{*}$ & $-.74 *$ & $-.75^{*}$ & $-1.58 * * *$ & $-1.59 * * *$ & $-1.60 * * *$ & .03 & .03 & .04 \\
\hline Partner and buddies & $-.84 *$ & $-.87^{*}$ & $-.87^{*}$ & $-1.78 * * *$ & $-1.80 * * *$ & $-1.78 * * *$ & $.65^{*}$ & $.65^{*}$ & $.65^{*}$ \\
\hline Kinship & .35 & .35 & .33 & $-.84^{*}$ & $-.84^{*}$ & $-.91 *$ & -.43 & -.43 & -.40 \\
\hline Colleagues & .03 & .06 & .04 & $-1.23 * *$ & $-1.21 * *$ & $-1.30 * *$ & $-1.13^{* *}$ & $-1.13^{* *}$ & $-1.09 * *$ \\
\hline Duration of relationships & $.04 * * *$ & $.04 * * *$ & $.04 * * *$ & $.03 * * *$ & $.03 * * *$ & $.03 * * *$ & $.02^{* *}$ & $.02^{* *}$ & $.02 * *$ \\
\hline \multicolumn{10}{|l|}{ Sex (Ref. Male) } \\
\hline Female & .39 & .38 & .38 & $.56^{*}$ & $.55^{*}$ & $.56^{*}$ & .16 & .17 & .16 \\
\hline \multicolumn{10}{|l|}{ Birth cohort (Ref. 1950-55) } \\
\hline $1970-75$ & $.57^{* *}$ & $.58 * *$ & $.58 * *$ & $.87 * * *$ & $.87^{* * *}$ & $.90 * * *$ & -.03 & -.03 & -.04 \\
\hline \multicolumn{10}{|l|}{ Level of education (Ref. Low secondary) } \\
\hline Upper secondary & -.01 & -.02 & -.03 & .91 & .91 & .86 & -.40 & -.40 & -.38 \\
\hline Vocational & .29 & .30 & .30 & .52 & .53 & .49 & -.55 & -.55 & -.54 \\
\hline Tertiary & .37 & .36 & .36 & .66 & .66 & .62 & -.63 & -.63 & -.62 \\
\hline \multicolumn{10}{|l|}{ Activity rate (Ref. Full-time) } \\
\hline Part-time (51-80\%) & .32 & .31 & .30 & -.04 & -.05 & -.10 & $-1.04 * *$ & $-1.04 * *$ & $-1.01 * *$ \\
\hline Part-time ( $50 \%$ or less) & .41 & .40 & .40 & -.41 & -.42 & -.39 & .27 & .27 & .26 \\
\hline Self-employed & -.05 & -.05 & -.06 & -.15 & -.15 & -.18 & -.16 & -.16 & -.15 \\
\hline Non-active & -.27 & -.29 & -.30 & -.31 & -.32 & -.35 & -.33 & -.33 & -.32 \\
\hline
\end{tabular}


Table 2. Logistic regressions of social capital (beta coefficients). (Cont.)

\begin{tabular}{|c|c|c|c|c|c|c|c|c|c|}
\hline & \multicolumn{3}{|c|}{ Network size } & \multicolumn{3}{|c|}{ Number of supportive ties received } & \multicolumn{3}{|c|}{ Trust in network members } \\
\hline & 1 & 2 & 3 & 1 & 2 & 3 & 1 & 2 & 3 \\
\hline \multicolumn{10}{|l|}{ Civil status (Ref. Married) } \\
\hline Divorced, widowed & .09 & .09 & .09 & .09 & .09 & .10 & -.35 & -.35 & -.36 \\
\hline Single & -.09 & -.10 & -.10 & -.17 & -.17 & -.18 & -.06 & -.06 & -.06 \\
\hline \multicolumn{10}{|l|}{ Citizenship (Ref. Foreigner) } \\
\hline Swiss & $.71^{*}$ & $.73^{*}$ & $.72^{*}$ & $.73^{*}$ & $.73^{*}$ & $.70^{*}$ & -.01 & -.01 & .01 \\
\hline $\mathbf{N}$ & 686 & 686 & 686 & 686 & 686 & 686 & 685 & 685 & 685 \\
\hline Log-Likelihood intercept only & -475.2628 & -475.2628 & -475.2628 & -445.9167 & -445.9167 & -445.9167 & -474.0106 & -474.0106 & -474.0106 \\
\hline Log-Likelihood full model & -419.8933 & -419.3965 & -419.3171 & -379.6671 & -379.5438 & -377.5497 & -434.1549 & -434.1549 & -433.5031 \\
\hline MacFadden $\mathbf{R}^{2}$ & 0.1165 & 0.1175 & 0.1177 & 0.1486 & 0.1486 & 0.1533 & 0.0841 & 0.0841 & 0.0855 \\
\hline
\end{tabular}

Notes: Non-active: non-employed, unemployed, retired, invalid; ${ }^{*} p<0.05,{ }^{* *} p<0.01,{ }^{* * *} p<0.001$.

Table 3. Logistic regressions of social capital (beta coefficients).

\begin{tabular}{|c|c|c|c|c|c|c|c|c|c|}
\hline & \multicolumn{3}{|c|}{ Network density } & \multicolumn{3}{|c|}{ Network transitivity } & \multicolumn{3}{|c|}{ Betweenness centrality } \\
\hline & 1 & 2 & 3 & 1 & 2 & 3 & 1 & 2 & 3 \\
\hline Network spatial dispersion & $-.21 * * *$ & $-.22 * * *$ & $-.23 * * *$ & $-.23 * * *$ & $-.25 * * *$ & $-.29 * * *$ & $.15^{* *}$ & $.13^{*}$ & $.16^{* *}$ \\
\hline Distant visits & & .0003 & -.0004 & & .0005 & $-.0024 *$ & & .0006 & .0019 \\
\hline Network spatial dispersion $\mathrm{x}$ distant visits & & & .0002 & & & $.0008^{*}$ & & & -.0004 \\
\hline \multicolumn{10}{|l|}{ Migration histories (Ref. 0-10 km) } \\
\hline $11-40 \mathrm{~km}$ & -.35 & -.35 & -.35 & -.25 & -.25 & -.25 & -.11 & -.11 & -.11 \\
\hline $41-100$ km & .05 & .06 & .06 & .03 & .04 & .04 & -.26 & -.25 & -.25 \\
\hline $101-500 \mathrm{~km}$ & .10 & .11 & .10 & .36 & .37 & .33 & -.37 & -.35 & -.34 \\
\hline Abroad & .27 & .29 & .29 & $.71^{*}$ & $.72 *$ & $.72 *$ & -.42 & -.40 & -.39 \\
\hline \multicolumn{10}{|l|}{ Network composition (Ref. Nuclear family) } \\
\hline Female friends & $-.66^{*}$ & $-.67 *$ & $-.66^{*}$ & $-.69 *$ & $-.72 * *$ & $-.69 * *$ & $.96 * * *$ & $.94 * * *$ & $.92 * * *$ \\
\hline Family of origin & -.24 & -.23 & -.21 & $-.70^{*}$ & $-.70^{*}$ & $-.63^{*}$ & $.64^{*}$ & $.64^{*}$ & .60 \\
\hline Sibling & -.14 & -.13 & -.13 & $-.65^{*}$ & $-.62 *$ & $-.61 *$ & .42 & .45 & .44 \\
\hline Partner and buddies & -.29 & -.27 & -.27 & .02 & .05 & .04 & .68 & .73 & .69 \\
\hline Kinship & -.35 & -.34 & -.33 & $-.82^{*}$ & $-.81^{*}$ & $-.73^{*}$ & .26 & .27 & .23 \\
\hline Colleagues & $-2.17^{* * *}$ & $-2.19 * * *$ & $-2.17^{* * *}$ & $-1.18^{* *}$ & $-1.21 * *$ & $-1.12 * *$ & $.88^{*}$ & $.84^{*}$ & $.80^{*}$ \\
\hline
\end{tabular}


Table 3. Logistic regressions of social capital (beta coefficients). (Cont.)

\begin{tabular}{|c|c|c|c|c|c|c|c|c|c|}
\hline & \multicolumn{3}{|c|}{ Network density } & \multicolumn{3}{|c|}{ Network transitivity } & \multicolumn{3}{|c|}{ Betweenness centrality } \\
\hline & 1 & 2 & 3 & 1 & 2 & 3 & 1 & 2 & 3 \\
\hline Duration of relationships & -.01 & -.01 & -.01 & .01 & .01 & .01 & $-.03 * *$ & $-.03 * *$ & $-.03 * *$ \\
\hline \multicolumn{10}{|l|}{ Sex (Ref. Male) } \\
\hline Female & .12 & .13 & .13 & -.32 & -.31 & -.31 & .39 & .41 & .41 \\
\hline \multicolumn{10}{|l|}{ Birth cohort (Ref. 1950-55) } \\
\hline $1970-75$ & -.38 & -.39 & -.39 & -.36 & -.37 & -.39 & -.18 & -.18 & -.16 \\
\hline \multicolumn{10}{|c|}{ Level of education (Ref. Low secondary) } \\
\hline Upper secondary & -.27 & -.27 & -.26 & -.35 & -.35 & -.32 & .40 & .39 & .40 \\
\hline Vocational & -.48 & -.48 & -.47 & -.52 & -.54 & -.52 & .29 & .26 & .27 \\
\hline Tertiary & -.44 & -.44 & -.43 & $-.77^{*}$ & $-.77^{*}$ & $-.75^{*}$ & .46 & .45 & .46 \\
\hline \multicolumn{10}{|l|}{ Activity rate (Ref. Full-time) } \\
\hline Part-time (51-80\%) & -.38 & -.38 & -.36 & -.30 & -.30 & -.24 & .27 & .27 & .25 \\
\hline Part-time ( $50 \%$ or less) & .21 & .22 & .22 & .20 & .21 & .19 & -.05 & -.04 & -.03 \\
\hline Self-employed & .20 & .20 & .21 & .13 & .13 & .16 & -.33 & -.35 & -.36 \\
\hline Non-active & -.42 & -.41 & -.40 & -.02 & .00 & .03 & -.39 & -.37 & -.38 \\
\hline \multicolumn{10}{|l|}{ Civil status (Ref. Married) } \\
\hline Divorced, widowed & -.04 & -.04 & -.04 & .01 & .02 & -.01 & .10 & .11 & .12 \\
\hline Single & .48 & $.49 *$ & $.49 *$ & $.70 * *$ & $.72 * *$ & $.73 * *$ & .09 & .09 & .09 \\
\hline \multicolumn{10}{|l|}{ Citizenship (Ref. Foreigner) } \\
\hline Swiss & -.17 & -.18 & -.17 & -.05 & -.07 & -.03 & -.08 & -.10 & -.11 \\
\hline $\mathbf{N}$ & 686 & 686 & 686 & 686 & 686 & 686 & 625 & 625 & 625 \\
\hline Log-Likelihood intercept only & -475.4990 & -475.4990 & -475.4990 & -474.6561 & -474.6561 & -474.6561 & -433.2098 & -433.2098 & -433.2098 \\
\hline Log-Likelihood full model & -435.3570 & -435.0439 & -434.8271 & -423.9000 & -423.2359 & -420.0171 & -392.5131 & -391.7540 & -391.1012 \\
\hline MacFadden $\mathbf{R}^{2}$ & 0.0844 & 0.0851 & 0.0855 & 0.1069 & 0.1083 & 0.1151 & 0.0939 & 0.0957 & 0.0972 \\
\hline
\end{tabular}


live on average close by. When the interaction effect is included in the model, the effect of social distance on the number of emotional support ties becomes positive $(\beta=.0021)$ and significant at $p<.1$ level (significance level not shown in the table because $p>.05$ ).

\section{Discussion}

Physical distance and travel play a crucial role in building trust and support relationships with and among significant relatives and friends. As obvious as this statement might be, insight into how migration, social visits and physical distance are related to social capital has been lacking so far. With this article, we analysed personal networks in Switzerland and we aimed to better understand this issue by investigating whether social visits moderate the effects of distance on social capital.

The strong influence of physical distance on social capital is confirmed by the results of our analysis. Migrants have more spatially dispersed networks, which, in turn, are associated with a higher number of emotional support ties compared to respondents with spatially close networks. This is in line with previous research on family networks (Widmer \& Viry, 2017), which shows that large networks require people to build and maintain significant relationships beyond their most proximate environment. But at the same time, individuals with more spatially dispersed networks have lower trust in their significant others. They also have higher bridging social capital than those with spatially close networks: they occupy a more central position between their significant others who are less likely to emotionally support each other. Migration measured by the residential distance from birthplace over the life course proved to have little effect on social capital when controlled for spatial dispersion, type and duration of relationships.

Only mixed support was found for the hypothesis that distant visits mitigate the effect of spatial dispersion on social capital, in particular by bringing migrants' geographically distant relatives and friends together. In line with our expectation, people who frequently visit and host their far-flung relatives and friends have more transitive networks than those who meet them less often. The predicted positive relationship between distant visits and number of supportive ties revealed to be more complex than expected. Frequent long-distance social visits are related to fewer emotional support ties, possibly because travelling long distances requires important resources and effort, which is restricted to only a few significant people. But the impact of social visits strongly differs depending on the network spatial dispersion. When associated with spatially closer networks, frequent visits are related to larger and non-transitive support networks. In contrast with far-flung networks, there seems that frequent visits to relatives and friends living at short or medium distance is less about bringing important people or circles together than cultivating a large and fragmented network of significant people.
Contrary to our expectations, our results do not provide evidence that people who are frequently visiting or hosting their far-flung relatives and friends are embedded in networks of higher density and higher trust than those who see them less frequently. Distant visits have little effect on network density, network size and social trust. A possible explanation is that social visits do not adequately capture the collective process by which family and friendship networks establish norms of solidarity and reciprocity, and a strong sense of togetherness at a broader spatial scale. Families and friends may establish these norms through regular social visits but also shared practices, routines and narratives (Finch, 2007), such as in some diasporas, military or seafaring families, for example. Studies on transnational families have documented that intimacy and a collective sense of family can persist without necessarily intermittent co-presence among people, through mediated interaction, emotional and material expressions of care (e.g., Drotbohm, 2009; Parreñas, 2005; Uy-Tioco, 2007). Social visits and travel as measured in this study, may better capture connectivity and meetings with significant people on a dyadic basis (for a critical view, see Bissell, 2013; Holdsworth, 2013). Multi-local living with significant relatives and friends spread out in multiple locations may also make it more difficult for migrants to bring these people in touch with one another despite intensive travel. Interestingly, the absence of any effect of distant visits on trust suggests a network effect that goes beyond dyadic relationships (Coleman, 1988). Finally, existing literature suggests that individuals are more likely to travel further to visit parents, siblings and children, whereas significant relationships with friends and colleagues are more likely to be local (e.g., Pollet et al., 2013; Widmer \& Viry, 2017), which is also confirmed by our data. Distant visits would then play a more important role in maintaining cohesion within the family of origin than in bringing together different social circles.

This study focused on face-to-face meetings and emotional support between respondents and their significant relatives and friends. We did not investigate mediated interaction and other forms of care and support, nor did we include social visits and trust for all network dyads or migration history for all network members. Moreover, we aggregated relational measures at the network level and did not use a multilevel approach to analyse the relationships at both the dyadic and network levels. Such investigations would be ideal using appropriate data. Nevertheless, our study has revealed novel insights into the change of personal networks resulting from migration and physical distance. In our globalised societies, individuals who nurture strong relationships with relatives and friends over large distances may rely on more people for emotional support. They might also exploit various resources and novel information from different geographical contexts to their advantage. But there is also a risk that they cannot benefit from a cohesive social group, which promotes a strong sense of security, group 
identification, bounded solidarity and mutual trust, and this despite intensive travel. The lack of support and risk of social isolation may be particularly high for disadvantaged and vulnerable populations who are remote from their proximity networks, such as poor migrants or single mothers of young children living far from their relatives.

\section{Acknowledgments}

This publication benefited from the support of the Swiss National Centre of Competence in Research LIVESOvercoming Vulnerability: Life Course Perspectives financed by the Swiss National Science Foundation. We wish to express our thanks to NCCR LIVES and the Swiss National Science Foundation. We are also grateful to anonymous reviewers for their valuable comments on earlier versions of this article.

\section{Conflict of Interests}

The authors declare no conflict of interests.

\section{References}

Ali, N., \& Holden, A. (2006). Post-colonial Pakistani mobilities: the embodiment of the 'myth of return' in tourism. Mobilities, 1(2), 217-242.

Axhausen, K. W., \& Kowald, M. (2015). Social networks and travel behaviour. Ashgate.

Baldassar, L., \& Merla, L. (Eds.). (2013). Transnational families, migration and the circulation of care: Understanding mobility and absence in family life. New York: Routledge.

Bissell, D. (2013). Pointless mobilities: Rethinking proximity through the loops of neighbourhood. Mobilities, 8(3), 349-367.

Boden, D., \& Molotch, H. (1994). The compulsion of proximity. In R. Friedland \& D. Boden (Eds.), Now here: Space, time and modernity (pp. 257-286). Berkeley and Los Angeles: University of California Press.

Brands, R. A. (2013). Cognitive social structures in social network research: A review. Journal of Organizational Behavior, 34(S1).

Brands, R. A., Menges, J. I., \& Kilduff, M. (2015) The leader-in-social-network schema: Perceptions of network structure affect gendered attributions of charisma. Organization Science, 26(4), 1210-1225.

Burt, R. S. (2009). Structural holes: The social structure of competition. Harvard University Press.

Coenders, G., Kogovšek, T., Hlebec, V., \& Coromina, L. (2014). Quality of social network data. In R. Alhajj \& J. Rokne (Eds.), Encyclopedia of social network analysis and mining (pp. 1433-1441). New York: Springer.

Coleman, J. S. (1988). Social capital in the creation of human capital. American Journal of Sociology, 94, 95-120.

Cronin, A. M. (2015). Distant friends, mobility and sensed intimacy. Mobilities, 10(5), 667-685.
De Carlo, I., \& Widmer, E. D. (2011). The fabric of trust in families: Inherited or achieved? In R. Jallinoja \& E. D. Widmer (Eds.), Families and kinship in contemporary Europe (pp. 216-233). Palgrave Macmillan.

Dekker, R., \& Engbersen, G. (2014). How social media transform migrant networks and facilitate migration. Global Networks, 14(4), 401-418.

Drotbohm, H. (2009). Horizons of long-distance intimacies: Reciprocity, contribution and disjuncture in Cape Verde. The History of the Family, 14(2), 132-149.

Elliott, A., \& Urry, J. (2010). Mobile lives. Abingdon: Routledge.

Finch, J. (2007). Displaying families. Sociology, 41(1), 65-81.

Freeman, L. C., \& Webster, C. M. (1994). Interpersonal proximity in social and cognitive space. Social Cognition, 12(3), 223-247.

Gauthier, J.-A., Bühlmann, F., \& Blanchard, P. (2014). Introduction: Sequence analysis in 2014. In P. Blanchard, F. Bühlmann, \& J.-A. Gauthier (Eds.), Advances in sequence analysis: Theory, method, applications (pp. 1-17). Springer.

Granovetter, M. S. (1973). The strength of weak ties. American Journal of Sociology, 78(6), 1360-1380.

Holdsworth, C. (2013). Family and intimate mobilities. Basingstoke: Palgrave Macmillan.

Kaufmann, V., Bergman, M. M., \& Joye, D. (2004). Motility: Mobility as capital. International Journal of Urban and Regional Research, 28(4), 745-756.

Kenny, D. A., Bond Jr, C. F., Mohr, C. D., \& Horn, E. M. (1996). Do we know how much people like one another? Journal of Personality and Social Psychology, 71(5), 928-936.

Krackhardt, D. (1987). Cognitive social structures. Social networks, 9, 109-134.

Krackhardt, D., \& Kilduff, M. (2002). Structure, culture and Simmelian ties in entrepreneurial firms. Social networks, 24(3), 279-290.

Larsen, J., Axhausen, K. W., \& Urry, J. (2006). Mobilities, networks, geographies. Ashgate.

Lubbers, M. J., Molina, J. L., Lerner, J., Brandes, U., Ávila, J., \& McCarty, C. (2010). Longitudinal analysis of personal networks. The case of Argentinean migrants in Spain. Social Networks, 32(1), 91-104.

Magdol, L., \& Bessel, D. R. (2003). Social capital, social currency, and portable assets: The impact of residential mobility on exchanges of social support. Personal Relationships, 10(2), 149-170.

Marsden, P. V. (1987). Core discussion networks of Americans. American Sociological Review, 122-131.

Mok, D., Wellman, B., \& Carrasco, J. (2010). Does distance matter in the age of the Internet? Urban Studies, 47(13), 2747-2783.

Morselli, D., Dasoki, N., Gabriel, R., Gauthier, J.-A., Henke, J., \& Le Goff, J.-M. (2016). Using life history calendars to survey vulnerability. In M. Oris, C. Roberts, D. Joye, \& M. E. Stähli (Eds.), Surveying human vulnerabilities across the life course (pp. 177-199). Springer. 
Mulder, C. H., \& van der Meer, M. J. (2009). Geographical distances and support from family members. Population, Space and Place, 15(4), 381-399.

Parreñas, R. (2005). Long distance intimacy: Class, gender and intergenerational relations between mothers and children in Filipino transnational families. Global Networks, 5(4), 317-336.

Pittinsky, M., \& Carolan, B. V. (2008). Behavioral versus cognitive classroom friendship networks. Social Psychology of Education, 11(2), 133-147.

Pollet, T. V., Roberts, S. G., \& Dunbar, R. I. (2013). Going that extra mile: Individuals travel further to maintain face-to-face contact with highly related kin than with less related kin. PloS One, 8(1).

Putnam, R. D. (1993). The prosperous community. The American Prospect, 4(13), 35-42.

Rainie, H., \& Wellman, B. (2012). Networked: The new social operating system. MIT Press.

Rousseeuw, P. J. (1987). Silhouettes: A graphical aid to the interpretation and validation of cluster analysis. Journal of Computational and Applied Mathematics, 20, 53-65.

Ryan, L., Sales, R., Tilki, M., \& Siara, B. (2009). Family strategies and transnational migration: Recent Polish migrants in London. Journal of Ethnic and Migration Studies, 35(1), 61-77.

Urry, J. (2007). Mobilities. Polity.

Urry, J. (2012). Social networks, mobile lives and social inequalities. Journal of Transport Geography, 21,
24-30.

Uy-Tioco, C. (2007). Overseas Filipino workers and text messaging: Reinventing transnational mothering. Continuum, 21(2), 253-265.

Valentine, G. (2006). Globalizing intimacy: The role of information and communication technologies in maintaining and creating relationships. Women's Studies Quarterly, 34(1/2), 365-393.

Viry, G. (2012). Residential mobility and the spatial dispersion of personal networks: Effects on social support. Social Networks, 34(1), 59-72.

Wellman, B. (2001). Physical place and cyberplace: The rise of personalized networking. International Journal of Urban and Regional Research, 25(2), 227-252.

Widmer, E. D. (2016). Family configurations: A structural approach to family diversity. Routledge.

Widmer, E. D., Aeby, G., \& Sapin, M. (2013). Collecting family network data. International Review of Sociology, 23(1), 27-46.

Widmer, E. D., \& Viry, G. (2017). Family inclusiveness and spatial dispersion: The spatial consequences of having large and diversified family configurations. Open Journal of Social Sciences, 5, 350-367.

Wittel, A. (2001). Toward a network sociality. Theory, Culture \& Society, 18(6), 51-76.

Wrzus, C., Hänel, M., Wagner, J., \& Neyer, F. J. (2013). Social network changes and life events across the life span: A meta-analysis. Psychological Bulletin, 139(1), 53-80.

\section{About the Authors}

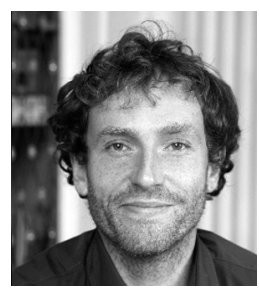

Gil Viry is Lecturer in Sociology at the University of Edinburgh. His research interests bridge the intersection of spatial mobilities, social networks, family and personal life. He is especially interested in exploring the role played by physical distance and mobility behaviours (travel, commutes, migration and digital mobility) in individuals' social and professional integration over their life courses. More information about Gil's research and current activities can be found here: https://gilviry.com

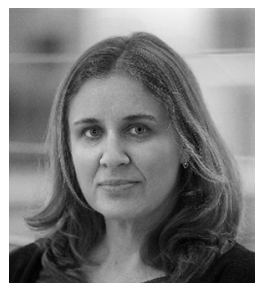

Olga Ganjour is a Post-Doc Researcher at the Department of Sociology at the University of Geneva. Her research interests include family studies, social networks, mobility, life course and welfare state regimes. She mainly uses quantitative research methods and social network analysis. She is currently engaged in the project on families and spatial mobility: 'Families in space' funded by NCCR LIVES and in the project of the Observatory of Families.

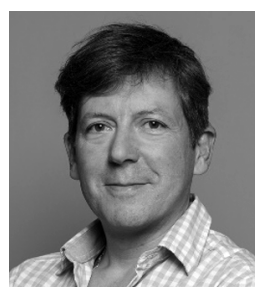

Jacques-Antoine Gauthier is a Senior Lecturer at the University of Lausanne's Life Course and Inequality Research Centre. Using a configurational perspective, his current research projects focus on modelling and analysing longitudinal life course data. Central to this analysis is the time-related construction of individual life trajectories and their interdependencies-especially when individuals experience major life transitions, such as the entry into the labour market, parenthood or retirement. 


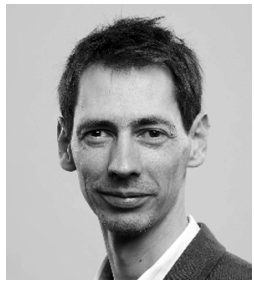

Emmanuel Ravalet is an Engineer with a PhD in Economics from the University of Lyon (France) and a PhD in Urban Studies from INRS-UCS (Montreal, Canada). He works in the Laboratory of Urban Sociology (LaSUR) at EPFL, Lausanne, Switzerland and at Mobil'Homme, a company he founded in 2014. His main research themes concern work-related mobilities, energy consumptions, new mobility services and local economic development.

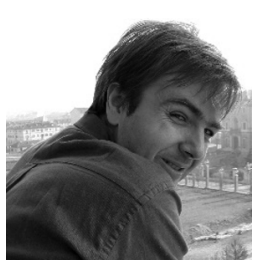

Eric D. Widmer is Full Professor of Sociology at the University of Geneva. His long-term research interests include intimate ties, family and other interpersonal relations, life course research and social networks. He has developed an understanding of families as complex configurations of interdependencies, always on the move in the life course. A description of various empirical research as well as a list of references, scientific conferences and public interventions on family configurations are available at www.edwidmer.org 


\section{COGITATIO}

\section{Appendices}

Appendix A. Descriptive statistics of the network size, network structure and trust in network members before dichotomization.

\begin{tabular}{llllllr}
\hline Statistics & Mean & Median & SD & Range & Kurtosis & Skewness \\
\hline Network size & 3.74 & 3.50 & 2.24 & $0-17$ & 8.16 & 1.55 \\
\# Support ties & 4.4 & 4 & 2.02 & $1-17$ & 7.45 & 1.39 \\
Trust & 4.51 & 4.67 & 0.58 & $1-5$ & 7.81 & -1.60 \\
Network density & 0.62 & 0.6 & 0.27 & $0-1$ & 2.05 & -0.22 \\
Network transitivity & 0.67 & 0.75 & 0.35 & $0-1$ & 2.38 & -0.79 \\
Betweenness centrality & 0.28 & 0.17 & 0.30 & $0-1$ & 2.64 & 0.85 \\
\hline
\end{tabular}

Appendix B. Measures of the strength of association between the network size, network structure and trust after dichotomization.

\begin{tabular}{|c|c|c|c|c|c|c|c|c|c|c|}
\hline & \multicolumn{2}{|c|}{$\begin{array}{l}\text { Network } \\
\text { transitivity }\end{array}$} & \multicolumn{2}{|c|}{$\begin{array}{c}\text { Betweenness } \\
\text { centrality }\end{array}$} & \multicolumn{2}{|c|}{ \# Support ties } & \multicolumn{2}{|c|}{ Trust } & \multicolumn{2}{|c|}{ Network size } \\
\hline & V & $\mathrm{Chi}^{2}$ & V & $\mathrm{Chi}^{2}$ & $\mathbf{V}$ & $\mathrm{Chi}^{2}$ & V & $\mathrm{Chi}^{2}$ & V & $\mathrm{Chi}^{2}$ \\
\hline Density & 0.57 & $256.47 * * *$ & 0.25 & $51.88 * * *$ & 0.04 & 1.08 & 0.34 & $91.07 * * *$ & 0.14 & $16.787^{* * *}$ \\
\hline Transitivity & & & 0.58 & $265.61 * * *$ & 0.05 & 2.07 & 0.28 & $65.00 * * *$ & 0.09 & $6.63 * *$ \\
\hline Centrality & & & & & 0.30 & $72.43^{* * *}$ & 0.14 & $16.50 * * *$ & 0.22 & $37.91 * * *$ \\
\hline Support ties & & & & & & & 0.09 & $6.73 * * *$ & 0.62 & $313.65 * * *$ \\
\hline Trust & & & & & & & & & 0.04 & 1.08 \\
\hline
\end{tabular}

Notes: $\mathrm{V}=$ Cramer's $\mathrm{V} ;^{*} \mathrm{p}<0.05,{ }^{* *} \mathrm{p}<0.01,{ }^{* * *} \mathrm{p}<0.001$

Appendix C. Sample description.

\begin{tabular}{llrr}
\hline & & N & \% \\
\hline Sex & Male & 397 & 49 \\
& Female & 406 & 51 \\
\hline Birth cohort & $1950-55$ & 340 & 45 \\
& $1970-75$ & 413 & 55 \\
\hline Level of education & Low secondary & 87 & 11 \\
& Upper secondary & 53 & 64 \\
& Vocational & 508 & 19 \\
\hline Activity rate & University & 148 & 49 \\
& Full-time & 382 & 10 \\
& Part-time (51-80\%) & 77 \\
& Part-time (50\% or less) & 95 & 12 \\
& Self-employed & 125 & 16 \\
\hline Civil status & Non-active & 108 & 14 \\
& Married & 578 & 14 \\
& Divorced or widowed & 109 & 14 \\
\hline Citizenship & Single & 116 & 18 \\
& Foreigner & 144 & 659 \\
\hline
\end{tabular}

Note: Non-active: non-employed, unemployed, retired, invalid. 
Appendix D. Type of network composition (average number of citations).

\begin{tabular}{|c|c|c|c|c|c|c|c|}
\hline & $\begin{array}{l}\text { Female } \\
\text { friends }\end{array}$ & $\begin{array}{l}\text { Nuclear } \\
\text { family }\end{array}$ & $\begin{array}{l}\text { Family of } \\
\text { origin }\end{array}$ & Sibling & $\begin{array}{l}\text { Partner and male } \\
\text { friends }\end{array}$ & $\begin{array}{l}\text { Extended } \\
\text { kin }\end{array}$ & Colleagues \\
\hline $\mathbf{N}$ & 188 & 174 & 98 & 93 & 82 & 65 & 55 \\
\hline Cluster size (\%) & 25 & 23 & 13 & 12 & 11 & 8 & 7 \\
\hline Partner & 0.36 & 1.00 & 0.95 & 0.62 & 1.00 & 0.63 & 0.58 \\
\hline Father & 0.13 & 0.03 & 0.78 & 0.05 & 0.04 & 0.14 & 0.09 \\
\hline Mother & 0.25 & 0.20 & 0.87 & 0.19 & 0.10 & 0.18 & 0.05 \\
\hline \# Sons & 0.41 & 1.03 & 0.23 & 0.14 & 0.02 & 0.34 & 0.42 \\
\hline \# Daughters & 0.42 & 1.10 & 0.19 & 0.17 & 0.05 & 0.37 & 0.25 \\
\hline \# Brothers & 0.10 & 0.07 & 0.15 & 0.81 & 0.00 & 0.15 & 0.13 \\
\hline \# Sisters & 0.13 & 0.08 & 0.23 & 0.95 & 0.01 & 0.38 & 0.00 \\
\hline \# Kin & 0.33 & 0.03 & 0.06 & 0.03 & 0.02 & 2.06 & 0.20 \\
\hline \# Female friends & 1.10 & 0.13 & 0.29 & 0.45 & 0.26 & 0.32 & 0.44 \\
\hline \# Male friends & 0.40 & 0.18 & 0.21 & 0.30 & 1.22 & 0.35 & 0.40 \\
\hline \# Other non-kin & 0.10 & 0.02 & 0.14 & 0.02 & 0.00 & 0.11 & 1.69 \\
\hline
\end{tabular}

Notes: Kin includes uncles, aunts, in-laws, cousins, godparents, grandparents, grandchildren, collaterals, and fictive kin. Other non-kin include colleagues and others; Reading: $36 \%$ of respondents in the 'female friends' composition type mentioned a partner. On average, they cited 1.1 female friends. 